\title{
Relief of chronic epiphora by transantral vidian neurectomy
}

\author{
A. E. W. GREGSON \\ Launceston, Tasmania
}

One of the constant side-effects of a successful transantral vidian neurectomy, well-known among otolaryngologists, is the interruption of the secreto-motor nerve supply to the lacrimal gland. Since this secreto-motor nerve supply is concentrated in the nerve of the pterygoid canal (vidian nerve) this is only to be expected.

This depression of lacrimation appears to be permanent, yet in some 300 recorded operations done over the last 7 years (Golding-Wood, I962; Hiranandani, I966; Gregson, I969) there has been no evidence of a subsequent keratoconjunctivitis sicca. It appears that the goblet cells of the conjunctiva take over and provide the eye with sufficient lubrication (Golding-Wood, I964).

The occurrence of a severe case of unilateral epiphora after a major injury to the eye and lacrimal apparatus seemed to be a good opportunity to investigate the value of this side-action of vidian neurectomy, for, from the rhinological viewpoint, the patient had nothing to lose, and from the ophthalmological viewpoint there might be much to gain.

\section{Case report}

A man aged 32 sustained a major injury to the left eye and periorbital tissues on March 6, 1965 , while felling trees.

\section{Examination}

On arrival in hospital he was apparently suffering from concussion. There were major lacerations of the left periorbital tissues. The anterior chamber of the left eye was opaque and the eye showed a loss of tension. It was thought that there might be a penetrating injury in the lower part of the cornea, but this was not certain.

Radiologically there was evidence of severe damage to the bone in the ethmoid labyrinth and a depressed fracture of the left malar bone.

On exploration under anaesthesia the bony damage to the medial part of the orbit was confirmed and it appeared that the lacrimal sac and canal were grossly damaged.

Fragments of bone and wood were removed from the periorbital tissues, but it was by no means certain that all had been removed. The lacerations were sutured.

The patient made an uneventful recovery, and, when seen on June 26,1965 , apart from loss of vision in the left eye, about which he was not greatly concerned, his only trouble was a persistent epiphora. Of this he complained bitterly, and it was apparent that he had to wipe away excess tears from the lower left eyelid every 2 or 3 minutes.

\section{Surgery}

It was decided to perform a left transantral vidian neurectomy, and this was done on September i 7 The recovery was uneventful and the patient returned home on the third post operative day.

When the case was reviewed one month later the epiphora was obviously controlled. 
Result

When the case was reviewed during November, 1968, over 3 years after the vidian neurectomy, the vision in the left eye was still poor although the patient could distinguish light from dark. The epiphora remains completely controlled and there is no evidence of keratoconjunctivitis sicca.

\section{Discussion}

When the patient was first seen it was considered that the traditional means of controlling the epiphora had a very poor prospect of success. In view of the trauma to the ethmoid labyrinth, dacryocystorhinostomy had certainly less hope than usual of success. Ablation of the lacrimal gland or its injection with alcohol seemed to carry an undue risk of orbital cellulitis in view of the probable presence of foreign bodies in the orbital tissues. As vidian neurectomy, in the three reports mentioned, carried a success rate of about 90 per cent., including the interruption of lacrimal activity, it appeared to offer much the best prospect, for it avoided the problem of a difficult and uncertain reconstructive operation on the one hand and the risk of orbital cellulitis on the other.

It is not suggested that the procedure should become an universal panacea for persistent epiphora. Some, at least, of these cases are thought to be due to hyperactivity in the goblet cells of the conjunctiva, and their nerve supply is completely dissociated from the vidian nerve. Nevertheless, vidian neurectomy may have a place in the treatment of this difficult condition, although it will be for ophthalmologists to decide where exactly that place lies.

\section{References}

GOLDING-WOoD, P. H. (1962) F. Laryng., 76, 969

(1964) Proc. roy. Soc. Med., 57, 394

GREGSON, A. E. W. (1969) J. Laryng., in press

HIRANANDANI, N. L. (1966) Ibid., 80, 902 